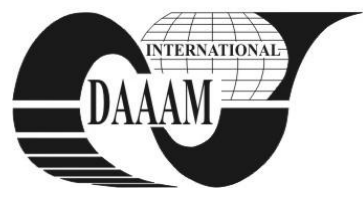

Annals of DAAAM for 2011 \& Proceedings of the 22nd International DAAAM Symposium, Volume 22, No. 1, ISSN 1726-9679 ISBN 978-3-901509-83-4, Editor B. Katalinic, Published by DAAAM International, Vienna, Austria, EU, 2011 Make Harmony between Technology and Nature, and Your Mind will Fly Free as a Bird Annals \& Proceedings of DAAAM International 2011

\title{
THE KINEMATIC AND DYNAMIC PERFORMANCES OF THE LOADING MECHANISM OF THE HIP JOINT WEAR SIMULATOR
}

\author{
PAKHALIUK, V[olodymyr] I[vanovich]; POLIAKOV, A[leksandr] M[ykhaylovich]; DESYATOV, I[van] \\ B[orisovich]; KALININ, M[ykhaylo] I[vanovich] \& STUPKO, M[axim] G[ennadyevich]
}

\begin{abstract}
In the presented work the evaluation of the kinematic and dynamic performances of the innovative design of the loading mechanism in the hip joint wear simulator - weartesting machine - is carried out. The loading mechanism is made on the basis of the accessories set for running (an electromechanical axis) produced by known FESTO Company, and provides the accuracy of reproducing the specified waveform of the applied force according to the ISO 14242 Standard. It is shown in the paper that owing to the equilibrium of the basic links of the mechanism, the dynamic loads arising in the process of work of the device are essentially less than the operating loads - which allows carrying out the drive control over the movement parameter of the axis' moving slide.

Key words: hip joint, endoprosthesis, wear, simulator, loading mechanism
\end{abstract}

\section{INTRODUCTION}

For decades, the interest in the joint simulating machines has undoubtedly increased, as it is widely recognized that this type of system only can realistically predict how the combination of biomaterials and prosthesis geometry will behave tribologically after the total joint replacement. The hip joint wear simulators (further - the Simulator) were developed for predicting the wear rate that the total hip replacements (prostheses) are likely to show inside the human body when attempting to reproduce in the laboratory conditions the physiological loads and motions.

In the Interdepartmental Laboratory of Biomechanics (SevNTU, Sevastopol, Ukraine) the Simulator has been developed. The testing device meets demands of the ISO/DIS 14242 Standard on the angular movement waveforms and the waveform of the loading cycle for the artificial hip joint to be tested. According to the ISO 14242, the femoral ball head in the Simulator is placed at the cross-section point of the three orthogonally related rotational axes with the specified ranges of the angular motions; the accuracy of reproducing is $\pm 3^{\circ}$ at the maxima and minima of the motion and $\pm 1 \%$ of the cycle time for phasing. Frequency of a cycle makes up $1 \mathrm{~Hz} \pm 0.1 \mathrm{~Hz}$. Force ranged from $0.3 \mathrm{kN}$ up to $3 \mathrm{kN}$ is applied vertically to the stationary acetabula component - cup.

The aim of this work is the evaluation of the kinematic and dynamic characteristics of the developed design of the Simulator's loading mechanism with the possibility of providing the right parameters on control of the drive of the given mechanism when reproducing the specified waveform of the load.

\section{DESIGN OF THE LOADING MECHANISM}

Mechanisms for creation load of the known existing simulators of a hip joint have been analysed. It has appeared, that practically in each of them are applied either pneumatic or hydraulic actuators for creation load (Saikko, 2005). Thus, at each test station, with the endoprosthesis installed in it, the force is applied vertically (as a rule, to the acetabula component) by means of individual pneumo- or the hydro cylinder.

As the simulator contains from 3 to 12 moving test stations and some stationary ones, the same quantity of individual actuators should be. Stationary stations are called soak stations and are used only in case of presence in the hip prosthesis friction pair of soft material, for example, ultra-high weight polyethylene (UHWPE), to consider quantity of an absorbed liquid under loading. As each testing of the endoprosthesises set is accompanied by the considerable quantity of cycles (to 3 million and more depending on demands of the Customer) in case of application of the hydro cylinders the probability is high that in the course of time there can be somewhere a leak of the operating fluid with subsequent possible "pollution" of the test environment that is inadmissible at conducting the tests of such objects of biomedicine as implants.

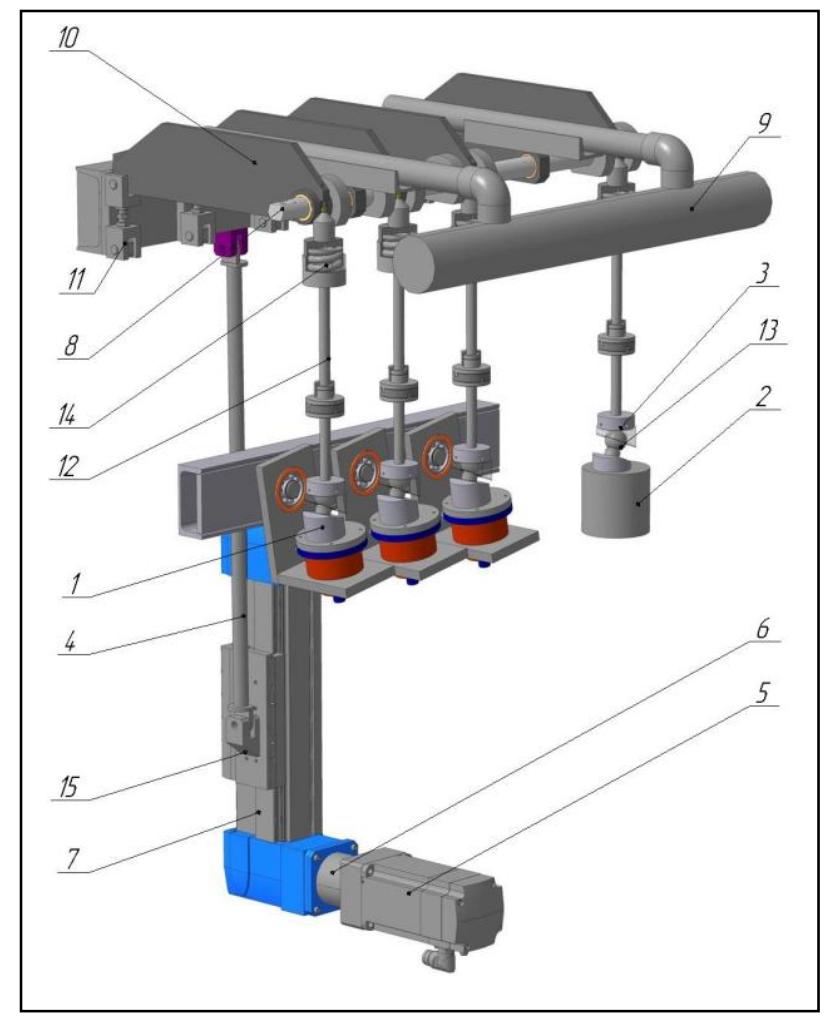

Fig. 1. The scheme of the loading mechanism of one block, wherein the part of the design of the simulator is not shown for convenience of visualisation of the loading chain: 1 - moving test station; 2 - stationary station of soak; 3 - acetabula prosthesis component (cup); 4 - connecting rod; 5 - servo motor; 6 - gear unit; 7 - electromechanical axis itself; 8 - pivot axis; 9 - counterbalance; 10 - two-arm lever; 11 - turnbuckle; 12 - vertical loading rack; 13 - head of endoprosthesis; 14 spring; 15 - electromechanical axis' slide 
The application of pneumatic cylinders as drives for creation loading also has the deficiencies. They are in the necessity of presence of the pneumatic station with corresponding requirements for preparation of air and in the raised noise. But the main shortcoming is that the existing pneumatic drives technically are not in the condition to provide the reproduction of the loading cycle waveform, presented in the ISO 14242 Standard (very sharp peaks), at necessary frequency $1 \mathrm{~Hz}$, as the proportional valve of pressure at the specified frequency can iterate only seven points but it is necessary to reproduce more than twenty ones.

Therefore, for the first time when designing the loading mechanism was used the mechatronics electric drive (the new generation of electromechanical axis produced by FESTO Company) which does not demand presence of the additional stations of air or hydraulics and is less noisy and easy controllable. On the basis of tentative evaluations the axis with toothed belt drive EGC-120-50-TB-KF-50H-GK-ZUB-2MY2X and with slide's working stroke of $50 \mathrm{~mm}$ (***, 2010), servo motor EMMS-AS-100-S-RSB, and gear unit EMGA-80-P-G3SAS-100 (***, 2009) have been accepted.

The specified simulator contains two blocks (Pakhaliuk et al., 2010). The scheme of the loading mechanism of one block is presented in fig. 1 .

\section{DYNAMICS OF THE LOADING MECHANISM}

The well-known equation of dynamics is used for the mechanism analysis and the control system synthesis (Artobolevskiy, 1988)

$$
M_{m}-M_{r}=J_{R} \varepsilon+\frac{\omega^{2}}{2} \frac{d J_{R}}{d \varphi}
$$

where $M_{m}, M_{r}$ are the reduced driving moment and the reduced moment of resistance forces; $\varepsilon, \omega, \varphi$ are the angular acceleration, angular velocity, and rotation angle of the reduction link; $J_{R}$ is the reduced mass moment of inertia of the mechanism that is calculated according to $(* * *, 2010)$.

Taking into account that in the loading mechanism there is the external force acting on the vertical rack 12 of each of four test stations, the reduced moment of resistance forces can be expressed by the following relation: $M_{r}=\frac{\left(F_{r}+F_{f}\right) v_{c a r}}{\eta_{\text {red }} \eta_{\text {belt }} \eta_{\text {bear }} \omega}$, where $F_{r}$ is the total effective resistance force on electromechanical axis' slide 15 from four stations; $F_{f}$ is the maximum no-load resistance to shifting of axis 7 (***, 2010); $\eta_{\text {red }}, \eta_{\text {belt }}, \eta_{\text {bear }}$, are the efficiencys of the gear unit (***, 2009), of the toothed belt drive, and of the rolling-contact bearing couple.

Knowing the changes of variables $M_{r}$ and $\varepsilon$ in formula (1) we can get changes of the reduced driving moment $M_{m}$ during the cycle, and thus the servo motor's control law.

\section{DISCUSSION}

The chart of slide movement $s_{c a r}=s_{c a r}(t)$ in accordance with the requirements of the ISO 14242 Standard was based on 22 points and was subsequently obtained in analytical form by the spline-interpolation. This gave the opportunity to calculate analytically derivatives $v_{c a r}=\frac{d s_{c a r}}{d t}$ and $a_{c a r}=\frac{d v_{c a r}}{d t}, \quad$ and, consequently, the motor kinematic parameters (fig. 2).

The servo motor's driving moment $M_{m}$ required to implement the demanded task was determined by solving the inverse dynamics problem (1). It was found that at each moment of time its value is very close to the values of the moment of resistance forces $M_{r}$. Therefore, the moments of inertial forces to be appeared during the work of the mechanism are negligible and do not exceed $3.5 \%$ relative to the moment of resistance forces at each instant of time.

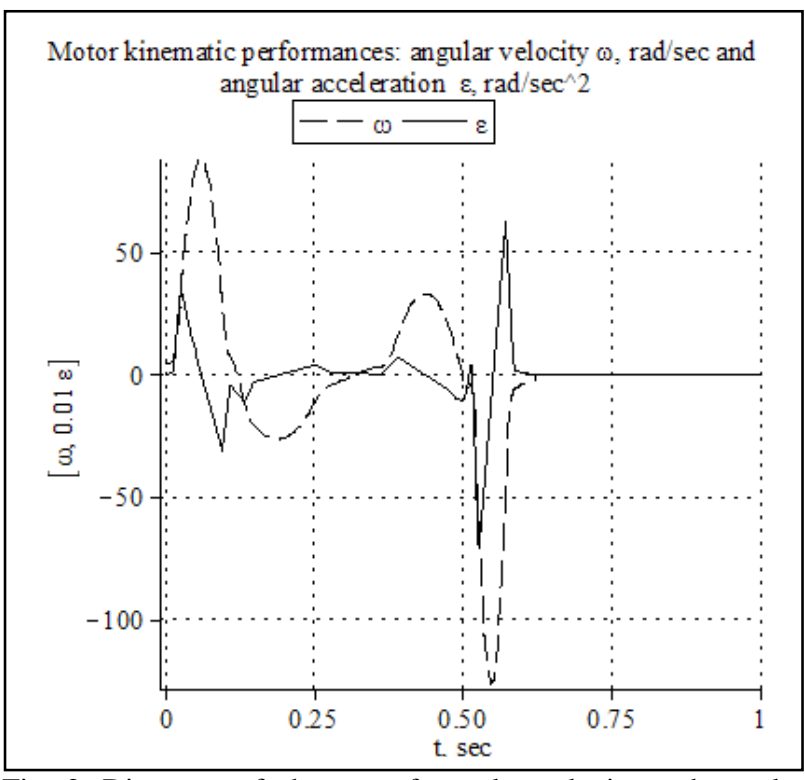

Fig. 2. Diagrams of changes of angular velocity and angular acceleration of the servo motor

\section{CONCLUSION}

For the first time when designing the Simulator's loading mechanism was used the electromechanical axis having a number of advantages in comparison with other kinds of drives. The simple and reliable method of an evaluation of dynamics of the mentioned mechanism and getting the servo motor's control law which analytically confirmed the correct choice of size of the electromechanical axis and its working capacity under the specified conditions, is offered. It also is confirmed by natural tests at the Simulator. Thus, the results of dynamic analysis of the mechanism showed the weak dynamics of the upper loading unit. The magnitude of the maximum value of the reduced driving moment does not exceed $6.23 \mathrm{Nm}$ (see fig 2), while the maximum driving moment of the servo motor is $9.2 \mathrm{Nm}(* * *$, 2009). Further, the motor's control laws in modelling devices for tests of the spine, of artificial limbs of extremities, of artificial joints and implants will be in a similar way obtained.

\section{REFERENCES}

Artobolevskiy, I. I. (1988). The Theory of Machines and Mechanisms, Nauka, Moscow

Pakhaliuk, V. I.; Desyatov, I. B. \& Manchuk, V. I. (2010). An improvement of design of the hip joint wear simulator, Annals of DAAAM for 2010 \& Proceedings of the 21st International DAAAM Symposium, ISSN 1726-9679, ISBN 978-3-901509-73-5, Katalinic, B. (Ed.), pp. 829-831, DAAAM International, Vienna, Austria

Saikko, V. (2005). A 12-station anatomic hip joint simulator, Proc. Inst. Mech. Eng., 219, Part H, 437-448

*** (2009) http://www.festo.com/net/SupportPortal/Downloads/ 10273/EMMS-AS_ENUS.pdf - Servo Motors EMMS-AS guide, Accessed on: 2011-01-10

*** (2010) http://xdki.festo.com/xdki/data/doc_ENGB/PDF/ EN/EGC-TB_EN.PDF - Toothed belt axes EGC-TB-KF, with recirculating ball bearing guide, Accessed on: 2011$01-23$ 